\title{
TEACHING VOCABULARY THROUGH CORPUS TO THE STUDENTS OF GRADUATION
}

\author{
Abdul Majeed Rana \\ Lecturer Associate Researcher of Management Sciences, ILMA University Karachi, Pakistan

\section{Zanib Amin} \\ Head of English Department, Sheikh Khalifa Bin Zayed Arab Pakistan School Abu Dhabi
}

\begin{abstract}
This study focuses on teaching vocabulary through corpus. Vocabulary is backbone of language learning process and its teaching has primary importance in teaching a language. The use of corpus is the most modern and the latest method which can be used to teach vocabulary at graduate level. With the sudden rise of the use of data through mobiles/computers, this method has got unchallenging repute. The researcher used the corpus of English text books of Graduation level of the Punjab University to teach vocabulary items. AntConc 3.5.7 was used as the tool. The students of graduate level were selected from Govt. Degree College, Kamoke, Gujranwala and divided into control and experimental groups. The use of pre-test taken by the control group, helped the researcher to find out the existing knowledge of the students. Only the top 20 vocabulary items were selected. Their selection was based on their frequency. Multiple techniques were used to teach and enhance vocabulary. The experimental group was targeted by the researcher four weeks with the help of four lesson plans on different type of vocabulary items. The post-test exhibited their improvement. The data was analyzed numerically and presented through percentage paragraph, tables and charts. The analysis of data proved that corpus based vocabulary teaching is far better than the earlier methods applied for the purpose of vocabulary teaching.
\end{abstract}

Key words: Corpus; Control Group; Experimental Group; Graduate Level; Language; Learning; Pre-Test; Post-Test; Teaching; Vocabulary.

Cite this Article: Abdul Majeed Rana and Zanib Amin, Teaching Vocabulary Through Corpus to The Students of Graduation, International Journal of Management, 11(12), 2020, pp. 1190-1204.

http://iaeme.com/Home/issue/IJM?Volume=11\&Issue=12

\section{INTRODUCTION}

\subsection{Corpus and Its Importance}

A 'corpus' is a large collection or database of machine-readable texts involving natural discourse in diverse contexts (Bernardini 2000). Such discourses can be spoken, written, 
computer-mediated, spontaneous, or scripted and may represent a variety of genres (for example everyday conversations, lectures, seminars, meetings, radio and television programs, and essays). Corpora have been used not only in language instruction and learning, but also in teaching disciplinary content, e.g., linguistics. In the teaching and learning of a second language (L2) or foreign language (FL), vocabulary is an essential component of all comprehension (Folse, 2010). Whether in real-world tasks such as asking for travel information or in academic tasks such as textbook reading, vocabulary is essential for the success of language learners. Teachers in content-area classes (such as introduction to psychology and introduction to chemistry) frequently teach content-specific vocabulary but are not aware of the challenges that L2 and FL learners encounter because they do not know the specialized vocabulary or the basic words surrounding the content-specific vocabulary. The integration of corpus in the field of English as a Foreign Language (EFL) results in a big shift in both 'methodology and ideology' (Binkai, 2012). Before corpora, linguistic descriptions have relied on what native-speakers know about language, or what they perceive language to be, rather than how language is used. Thanks to corpora, we have gained a better understanding of the contextual use of language, and we have developed new insights into language structure (Tsui, 2004). Corpora provide a number of examples of an item searched in its context of use, but it does not give the meaning of the word or phrase on the screen.

\subsection{Corpus Linguistics}

Corpus linguistics nowadays is perhaps most readily associated in the minds of linguists with searching through screen after screen of concordance lines and wordlists generated by computer software, in an attempt to make sense of phenomena in big texts or big collections of smaller texts. This method of exegesis based on detailed searches for words and phrases in multiple contexts across large amounts of text can be traced back to the thirteenth century, when biblical scholars and their teams of minions pored over page after page of the Christian Bible and manually indexed its words, line by line, page by page. Concordancing arose out of a practical need to specify for other biblical scholars, in alphabetical arrangement, the words contained in the Bible, along with citations of where and in what passages they occurred.

The etymology of concordantia is the Latin cum, meaning 'with', and cor meaning 'heart', which ties in with the original ideological underpinning of this painstaking endeavour, namely to underscore the claim that the Bible was a harmonious divine message rather than a series of texts from a multitude of sources. Anthony of Padua (1195-1231) is associated with the first known (anonymous) concordance of the bible, the Concordantiae Morales, based on the Vulgate (the fifth-century Latin version of the Bible). A well-documented work around the same time was by Cardinal Hugo of St Caro (also referred to as St Cher), who in 1230, aided by a 500-strong team of Dominican monks at St James' convent in Paris, put together 'a word index' of the Vulgate (Bromiley 1997: 757; see also Tribble this volume). Since then numerous other concordances of the Bible have evolved, including Cruden's (1737),A Complete Concordance to the Holy Scriptures and Strong's 1890 Exhaustive Concordance of the Bible. Nowadays, computer concordancing programs replicate the work of 500 monks in microseconds.

\subsection{Role of Corpus in Teaching English}

The advent of corpora provides new methodologies for language study and changed linguists' approach in areas such as lexicography or English Language Teaching (ELT). With regard to ELT, there are several aspects of language pedagogy which demonstrate how corpus findings have been put to practical use. First of all, all major publishers use corpus data to compile dictionaries and teaching materials. If one wishes to publish a dictionary that reflects the way 
English is spoken every day, they need to obtain accurate information about the language and the only way to do so is to investigate the authentic use of English by its speakers.

\subsection{Role of Corpus in Teaching Vocabulary}

It is worth mentioning that corpus analysis leads scholars to the idea of the lexical syllabus an innovative approach to language teaching that directly uses corpus findings and organizes the content for teaching around frequent vocabulary. Sinclair and Renouf (1988) were the first authors who suggested the lexical syllabus following their work on the COBUILD project. Willis and Willis' (1988) were also interested in the lexical syllabus and they built the Collins COBUILD English Course on the basis of it.

Corpus data can also be directly used in the classroom in the form of data-driven learning (DDL). This methodology was first proposed by Johns (1991: 2) who claims that the language learner "is also a research worker whose learning needs to be driven by access to linguistics data". By exploring authentic language material, learners themselves identify common patterns in grammar and lexis, while the teacher only facilitates the whole process.

\subsection{English Language in Pakistan}

English in Pakistan is used as an official and a second language. It is spoken and used by a relatively small but extremely influential portion of country's population in the domain of government administration, law, the military, the higher education, commerce and mass media (Baumgardner 1993:43). According to Ghani (2003:105), English in Pakistan serves as a gateway to success, further education and white collar jobs. It is the language of higher education and wider education and not the home language of the population except in the upper strata of society where it is spoken as a status symbol.

Socially, English adopted as a second language has had a significant impact both economically and educationally. It continues to play an important role in the country's commercial and industrial development and outside the government sector. English is taught as the compulsory subject from the first grade in our curricula. English language teachers in Pakistan must approach teaching English as a SecondLanguage from the perspective of applied linguistics. Increase in the number of language institutes and their students also increasing interest of parents for their children to learn English can be a good evidence for the recent value of English.

\subsection{English Vocabulary}

Corpus software can easily generate lists of the most frequent words (whether lemmatized or as individual word-forms) in a given corpus. These enable the writer to establish the common core vocabulary that learners are likely to need as a priority as opposed to a more advanced vocabulary, which can be taught later (see O'Keeffe et al. 2007: Ch. 2). Frequency lists which 'band' vocabulary into the most frequent 1,000 words, 2,000 words, etc., can be the basis for organizing vocabulary for different levels of a course book. The syllabus of The Cobuild English Course (Willis and Willis 1987-8) with its lexical approach was determined by word frequency. The most frequent 700 words with their common patterns were taught in Level 1, the next 800 in Level 2, and so on (see Willis 1990). Frequency also helps the writer to priorities which members of large lexical sets - for example colors, foods, clothes - to teach first, or see which of two or three synonyms is more frequent (e.g. sofa or couch; eat breakfast or have breakfast) and identify the most frequent collocates of delexically verbs such as make and do. For writers of more specialist courses such as English for Academic Purposes courses, the Academic Wordlist created by Averill Coxhead (Coxhead 2000) from a corpus of 3,500,000 academic texts provides an invaluable resource of lists of 570 word families (excluding the top 
2,000 most frequent words in English) from which to devise a vocabulary syllabus (see Coxhead, this volume). Similarly, the Cambridge Learner Corpus of written scripts from Cambridge ESOL examinations provides writers of examination courses with information about typical errors made by candidates in those examinations, around which a syllabus area can be built. See Capel and Sharp (2008) as an example.

\subsection{Role of Vocabulary in The Four Skills}

Vocabulary is central to English language teaching because without sufficient vocabulary, students cannot understand others or express their own ideas. Lewis (1993) went further to argue, "Lexis is the core or heart of language" (p.89). Writing is undoubtedly a complicated skill to master for L2 learners (Richard, 2002). The difficulty stems from the fact that generating and organizing ideas and then translating them into readable text are time-consuming and longsought skills even for native speakers. According to Richards (2002), the complex skills which are used in writing require L2 learners to not only focus on planning and organizing skills in a higher level but also on spelling, punctuation, word choice skills in a lower level. This difficulty is especially aggravated when, language proficiency is weak. Based on previous research, lack of vocabulary knowledge makes writing a difficult task for L2 learners (Astika, 1993) and vocabulary plays a crucial role in writing quality (Walters \& Wolf, 1996). In addition, vocabulary is commonly considered as one of the main factors required for L2 proficiency as well. It is central to language and crucially important for L2 students.

\subsection{Statement of the Problem}

Corpus-based approach for teaching vocabulary to the students is more effective than traditional approaches. Through rote learning the students learn vocabulary but for the short time period. Furthermore, the students take such process of learning a boring one. Students are less interested and more boring. Even at graduation level they have the least idea to use computer to enhance vocabulary.

\subsection{Research Questions}

- How the corpus-based activities be used for teaching vocabulary at graduate level?

- What is the attitude of the students towards corpus-based vocabulary learning activities?

\subsection{Objectives}

The current study is to investigate the effectiveness of corpus-based vocabulary learning activities instead of using text books and dictionaries at graduate level and to investigate the attitude of the students towards corpus-based activities. This approach will not only make the process of vocabulary learning easier but also more interesting.

\subsection{Significance of the Research}

This study investigates the effectiveness of integrating corpus-based approaches to enhance the vocabulary of the students at graduate level. Specifically, this study aimed at finding out whether students who participated in this corpus-based project (the experimental group) acquired more incidental vocabulary than those who did not (the control group).

\section{LITERATURE REVIEW}

\subsection{Importance of Vocabulary}

All the words those a person knows and are uses. This is a list of words with their meanings especially in a book for learning a foreign language. Vocabulary can be defined as the words 
of a language, including single items and phrases or chunks of several words which covey a particular meaning, the way individual words do. Vocabulary addresses single lexical items words with specific meaning(s) but it also includes lexical phrases or chunks. Some online dictionaries such as the Merriam-Webster (2015) define vocabulary as "The words that make up a language; all of the words known and used by a person: words that are related to a particular subject." Similarly, Cambridge (2016) describes it as "The words that are known or used by a particular person, or that are used in a language or subject." Finally, Macmillan (2009-2016) also presents it as "All the words that a person knows; all the words in a particular language."

\subsection{Teaching Vocabulary at Graduate Level}

Teacher attitudes to vocabulary have changed a lot over recent years. The use of the word lexis (rather than the more familiar vocabulary) react a fundamental shift in understanding, attitude and approach. The increasing availability of corpora (large computerized databases of analyzable real conversations and other text), and dictionaries, grammar books and other resources based on them have revealed many surprising features of language that had been previously unrealized (Scrivener Jim, 2005). Teaching vocabulary is a crucial aspect in learning a language as languages are based on words (Alqahtani, 2015). It is almost impossible to learn a language without words; even communication between human beings is based on words. Recent research indicates that teaching vocabulary may be problematic because many teachers are not confident about the best practice in vocabulary teaching and at times do not know where to begin to form an instructional emphasis on word learning (Berne \& Blachowicz, 2008). Either teachers or students agree that acquisition of the vocabulary is a central factor in teaching a language (Walters, 2004). Teaching vocabulary is considered as one of the most discussed parts of teaching English as a foreign language. When the teaching and learning process takes place, problems would appear to the teachers. They have problems of how to teach students in order to gain satisfying results. The teachers should be concerned that teaching vocabulary is something new and different from student's native language. They also have to take into account that teaching English for young learners is different from adults. The teacher should prepare and find out the appropriate techniques, which will be implemented to the students.

\subsection{Vocabulary and Its Kinds}

The Two Vocabularies Generally speaking, there are two different types of vocabulary items; active and passive. Active vocabulary includes words that we expect our students not only to be able to identify and understand but also use in their everyday lives. Passive vocabulary includes words which they should recognize and understand, but need not use themselves, at least not yet. Both types of vocabulary are very important. Vocabulary has been discussed and divided into various types. Some are divided into two types: active and passive vocabulary. Gruneberg and Sykes (1991) distinguished the two types of vocabulary. The first type of vocabulary referred to the one that the students had been taught and that they were expected to be able to use. Meanwhile, the second one referred to the words which the students would recognize when they met them, but they would probably not be able to pronounce. Hatch and Brown (1995), indicated two kinds of vocabulary, namely as receptive vocabulary and productive vocabulary. Receptive vocabulary means words that learners recognize and understand when they are used in context, but which they cannot produce.

The type of vocabulary that learners recognize when they see or meet in reading text but do not use it in speaking and writing (Stuart, 2008). Meanwhile productive vocabulary is the words that the learners understand and are able to pronounce correctly and use constructively in speaking and writing. It consists of what is needed for receptive vocabulary plus the ability to speak or write at the appropriate time. Productive vocabulary can be addressed as an active process, because the learners can produce the words to express their thoughts to others (Stuart, 
2008). Vocabulary is crucial to be mastered by the learner in order to understand the language, vocabulary mastery is needed to express our ideas and to be able to understand other people's sayings. Hornby (1995) as cited in Alqahtani (2015) defined the mastery of vocabulary as complete knowledge or complete skill.

\subsection{Lexicon}

A lexicon, word hoard, wordbook, or word stock is the vocabulary of a person, language or a branch of knowledge. In linguistics, a lexicon is a languages inventory of lexemes. The word lexicon derives from the Greek, neuter of, meaning of or for words. A lexicon is the vocabulary of a language or subject. No hitter, go ahead run, and Baltimore chop, are art of the baseball lexicon. Lexicon is really dictionaries, though a lexicon usually covers an ancient language or the special vocabulary of a particular author or field of study.

\subsection{Lexis}

Lexis (or vocabulary refers to single words, or set of words that have a specific meaning, for example car, ick u, In the ed. Lexis is a term I linguistics referring to the vocabulary of a language, Lexis is a Greek term meaning word or speech. The adjective is lexical. The study of the lexis ad lexicon, or collection of words in a language, is called lexicology. The process of adding words and the word patterns to the lexicon of a language is called lexicalization.

\subsection{Difference Between Vocabulary and Lexis}

Vocabulary versus Lexis When we think of the term vocabulary we think of the words that people know (are able to use) or recognize. In the scale of language was can already see that vocabulary occupies a central position.

\section{Sounds - Words - Sentences}

But the term vocabulary refers to words alone. Lexis relates to not just words but element both above and below the word level, smaller elements such as particles (up in the phrasal verb step up) including bound morphemes (un as in unconscious) in addition to larger elements such as fixed expressions (raise your hands, on the fence about). In addition to differences in size lexis also relates to linguistic units which tend to co-occur but are not necessarily fixed such as collocations (black coffee, hot day, wonderful time). Looking at this more closely we can see that while vocabulary items are seen as being prey to grammatical rules, lexis sees grammar as being achieved (at least in part) by the words themselves.

\subsection{Importance of Corpus}

Any analysis of 'typical' or 'probable' choices depends on frequency analysis. The very mention of a choice being 'typical' or 'unusual' implies that, under given circumstances, it happens more or less often than other choices. For reliable frequency analysis, a corpus does not necessarily have to be immense, but it must be designed to be as representative as possible (see the chapters in Section I of this volume) and as fine-grained as needed to describe the circumstances associated with the variable choices. For example, McCarthy and Carter (2001) explain the need for fine-grained distinctions in spoken corpora to describe when ellipsis is and is not common. They find ellipsis to be rare in narratives, while it is common in many other genres of talk. Any corpus that did not include numerous conversational genres or any analysis which neglected to differentiate among them would fail to discover this pattern.

Frequency counts are not sufficient for describing grammar, however. Instead, they point to interesting phenomena that deserve further investigation and interpretation. As Biber et al. (2004) explain, we do not regard frequency data as explanatory. In fact, we would argue for the opposite: frequency data identifies patterns that must be explained. The usefulness of frequency 
data (and corpus analysis generally) is that it identifies patterns of use that otherwise often go unnoticed by researchers. (p. 176)

In corpus-based grammar studies, interpretations of frequency analyses come from a variety of sources. They can be based on cognitive principles such as the principle of 'end weight' (heavy, long constituents are harder to process than short constituents and so are placed at the ends of clauses); on aspects of linguistic theory, such as principles defined in Systemic Functional Linguistics; on the historical development of the language; or on reasonable explanations of the functions or discourse effect of a particular linguistic choice. Interpretation always includes human judgements of the impact of the language choices and speakers/writers' (usually subconscious) motivations in making these choices. Thus, a corpus linguistics perspective on grammar has not made human judgements superfluous; it has actually expanded the judgements and interpretations that are made.

\subsubsection{Use of Corpus to Teach Language}

A major potential benefit for the grammar classroom and related materials that corpus based approaches bring is the way that they lend themselves to what have become fashionable approaches to the role of the teacher and learner in the ELT classroom. In particular, corpusbased grammars lend themselves well to more autonomous learning and to inductive approaches that encourage the student to see patterns in the language evidence for themselves and test out their own hypotheses about structures and use. At its best this questioning, investigative approach puts the 'learner as researcher' in charge of finding REBECCA HUGHES some of their own answers to grammar points from large samples of data provided by a corpus and can also allow individual students to follow up questions that they are particularly motivated to find out about (see Gilquin and Granger, this volume).

These approaches come broadly under the umbrella of 'classroom and teacher-led' developments in corpus-based grammar teaching material and they are not necessarily connected either to the research base in academe or to published materials. Often the individual teacher who becomes interested in moving beyond intuitions and traditional approaches is a particular type of personality and has an unusual combination of skills and inclinations. He or she is often an IT-literate teacher comfortable with using new technology in front of a class, is often a keen champion of ITC in the language teaching classroom, and enjoys the challenging exploratory nature of students and teacher finding answers together. Like the teacher who enjoys teaching pronunciation and thrives on the technical aspects of teaching this, the grammar teacher who uses corpora has often been the exception rather than the norm in the ELT community. Although classroom-based activities that use the internet to access concordancing tools and corpora for student directed investigations of grammar are becoming more mainstream they have yet to be fully incorporated into teacher training programs for ELT (see McCarthy 2008). There are a number of reasons why this is the case (the next section dealing with some of the limitations for corpus-based grammar approaches may provide explanation for some of these) but the principles of modern language teaching can clearly be supported via connecting classrooms and corpora more effectively.

- Corpus-based grammar materials and approaches to teaching grammar that are based on corpora can be adapted to suit several very different approaches and individual learning styles. For the analytical individual, whether teacher or student, corpora provide tangible quantitative data on which to test out ideas about language or from which to develop materials for the grammar classroom.

- At a more practical level and whatever their approach, corpora can provide teachers with an immense variety of samples of language which can be adapted for any form of teacher-developed materials. 
- Corpus-based grammar materials lend themselves to task-based and communicative activities particularly well as they are readily adaptable to group and project work and autonomous learning contexts. The language learner can be encouraged to develop their own questions about grammatical points and investigate the answers for themselves via corpus examples.

- The teacher facing mixed ability groups will also find corpus-based grammar materials beneficial. With some preparation the same task framework can be used for groups with the same instructions but applied to different language points.

\subsubsection{Use of Corpus to Teach Vocabulary}

Corpus linguistics is a broad field that studies a representative body of language as it exists in authentic speech or text rather than language that is invented for the purpose of illustrating a certain linguistic construct or theory (Meyer, 2002; Murphy, 1996). Meyer (2002, p. xiii) referred to corpus linguistics as not only a linguistic field but also a methodology that presupposes that it is "important to base one's analysis of language on real data-actual instances of speech or writing - rather than on data that are contrived or "made-up".. Other characteristics of corpus studies include the use of computers for quantitative analysis and the use of qualitative techniques by researchers. Corpus studies can be used to study a wide range of language phenomena, including historical and stylistic conventions, discourse patterns, language acquisition, grammatical constructions, and vocabulary analyses (Teubert \& Cremakova, 2007).

Data-driven learning (DDL) refers to the use of a corpus of texts through the concordancing software when trying to find answers to linguistic questions by observing different uses of language. Although it is not a communicative approach, it has benefits such as being learnercentered, using authentic language, and promoting learner discovery (Allan, 2009). Data-driven learning (DDL) was defined by Johns and King (1991, p.iii) as "the use of computer-generated concordances in the classroom to get students to explore regularities of patterning in the target language, and the development of activities and exercises based on concordance output." Johns (1991) lays out the principles of DDL as follows:

- The learners discover the language through their own questions and the languagelearner is a researcher who has access to linguistic data.

- The computer acts as an informant answering the questions that the learners ask themselves.

- The basic computer tool is the concordancer. Thus, the concordances on a computer screen show all instances of a word or phrase in a key word in context (KWIC) format.

- The teacher is in the role of a facilitator in a student-centered classroom and concordancers are the important focus for learning. Corpus approach or data-driven learning approach (DDL) includes hypothesis formation while carrying out inductive corpus-based exercises, teacher's explicit explanations either to confirm or correct these hypotheses, and thus, hypothesis testing in terms of follow-up exercises regarding the task and output by learners (Chujo, Anthony \& Oghigian, 2009). One of the central principles of the corpus approach is that vocabulary and grammar are interrelated rather than distinctive from each other (Halliday, 1992; Sinclair, 1991 cited in Yoon \& Hirvela, 2004).

Vocabulary instruction is moving away from teaching words in isolation, and placing a greater emphasis on exposing learners to lexical items in authentic and meaningful contexts. Furthermore, there is a growing amount of evidence that much of the English language is 
formulaic which suggests that teaching vocabulary as separate from grammar has limitations (Balunda, 2009).

\section{RESEARCH METHODOLOGY}

\subsection{Type of Research}

The design of research was both qualitative and quantitative. The experimental research design was used to conduct the research. Researcher tried to get different results from the research conducted in Govt. Degree College Kamoke, Gujranwala. Researcher noted that being an Urdu medium institution, no special effort was being made there, on the part of teachers, to teach vocabulary at graduation level. Traditional grammar translation method is in practice in most of the government intuitions and this college was also no exception. The main focus of attention of the teachers was grammar and translating the material in first language. Limited vocabulary that used to come at hand while teaching text books was only the destination of teachers and students as well at this level. Data collection was vital part of the research, for which different means were selected. Following methods of data collection were adopted.

\subsection{Research Tools}

- Pre-Test

- Post-Test

\subsection{Sample/Subjects}

Only one sample was selected for the research and it was the group of students of Govt. Degree College Kamoke, Gujranwala, selected to be thought as an control and experimental group. Mixed ability students were selected through random selection for experimental group.

Subject: Teaching vocabulary at graduate level through corpus

Sex: $\quad$ Male students only

Age: $\quad 18$ to 25 years

Level: $\quad$ Graduate level

\section{DATA ANALYSIS}

This chapter investigates the data compiled by researcher. First the researcher made the corpus of four English textbooks of Graduate level in soft form in notepad, then used the corpus to choose nouns, verbs, adverbs and adjectives. twenty vocabulary items were selected which are used most of the time. The nouns, verbs, adverbs and adjectives were selected to analyze as vocabulary comprehension. From the English text books five nouns, five verbs, five adverbs and five adjectives have been analyzed and interpreted by the help of corpus 3.5.7.0. Ten vocabulary items were used for pre-test and ten used for post-test. All of the vocabulary items were taught to the students in detail. The students were analyzed after the learning. Researcher made four lesson plans and taught in different periods. The teacher explained to the students what a concordance is, how the corpus is made and showed them how the concordancer works. Then the students, working in pairs, received a corpus of four books of graduate level along with a set of language learning exercises designed by the teacher (the author of this paper). The aim of these tasks was to guide the students, analysis, and to make them aware about the use and function of some important vocabulary items present in the text.

\subsection{Pre-Test}

First of all, the researcher conducted a pretest to check the existing knowledge of the students. The researcher made the corpus of four English books of graduate level. The researcher selected 
top 10 vocabulary items as nouns, verbs, adverbs and adjectives. After choosing the vocabulary words the researcher made a pre-test question paper. The researcher gave the students just two questions. In the first question they were asked to highlight the different vocabulary words with the help of different colored highlighters. In the second question they were asked to write an essay by using the 10 words choose by the researcher with the help of corpus. Then the paper was given to the fifteen students of control group. They attempted both of the questions. They were sat with specific distance.

\section{Pre-Test Results}

Following Figure 1 and Table-I show the pre-test results of the students. The students were assessed before teaching. They were given a test (appendix-A) regarding verb, adverb, adjective and noun as vocabulary items. All of the items were given for different goal. The students' overall percentage was 61 as given in the table. Overall it was very low percentage at graduate level as the students don't have a good stuff of vocabulary. They were really need to learn, how to enhance vocabulary?

The highest numbers taken by the students were $90 \%$ as given in the chart and the lowest marks taken by the students were $50 \%$. Students at graduate level got $50 \%$ is low percentage. So there was a need to teach them vocabulary. After graduation they will get admission in masters, so their vocabulary should be strong. If the vocabulary will be strong they can learn in every field easily.

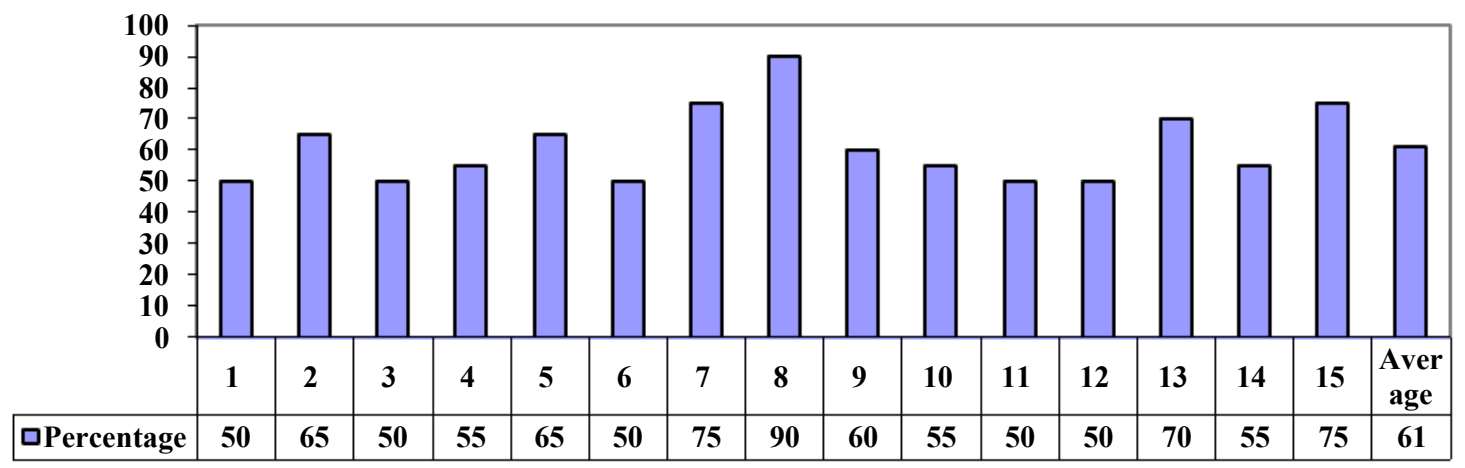

Figure 1

Table 1

\begin{tabular}{|c|c|c|c|c|}
\hline \multicolumn{5}{|c|}{ Pre-Test Results } \\
\hline $\begin{array}{c}\text { Sr. } \\
\text { No. }\end{array}$ & $\begin{array}{c}\text { Vocabulary } \\
\text { Test Q.1. out of } \\
\mathbf{1 0}\end{array}$ & $\begin{array}{c}\text { Vocabulary Test } \\
\text { Q.2. out of 10 }\end{array}$ & Obtained out of 20 & Percentage \\
\hline 1 & 6 & 4 & 10 & 50 \\
\hline 2 & 7 & 6 & 13 & 65 \\
\hline 3 & 5 & 5 & 10 & 50 \\
\hline 4 & 6 & 5 & 11 & 55 \\
\hline 5 & 6 & 7 & 13 & 65 \\
\hline 6 & 4 & 6 & 10 & 50 \\
\hline
\end{tabular}




\begin{tabular}{|c|c|c|c|c|}
\hline 7 & 7 & 8 & 15 & 75 \\
\hline 8 & 8 & 10 & 18 & 90 \\
\hline 9 & 5 & 7 & 12 & 60 \\
\hline 10 & 6 & 5 & 11 & 55 \\
\hline 11 & 5 & 5 & 10 & 50 \\
\hline 12 & 5 & 5 & 10 & 50 \\
\hline 13 & 8 & 6 & 14 & 70 \\
\hline 14 & 6 & 5 & 11 & 55 \\
\hline 15 & 8 & 7 & 15 & 75 \\
\hline
\end{tabular}

After conducting a pre-test, the researcher came to know the short comings of the students at graduate level in vocabulary. They were really need to enhance their vocabulary for their further studies as well. One who has a stock of good vocabulary, can learn more easily.

\subsection{Teaching Phase}

Putting in the mind the shortcomings of the students the researcher made four lesson plans to target four different type of vocabulary. The lesson plans were made on Noun, Verb, Adverb and Adjective. To teach the students researcher arranged a computer lab there in the college. The researcher already made the corpus so it was given to the students to learn them the use of corpus to enhance their vocabulary words.

\subsubsection{Corpus Assistance}

Corpus software AntConc. 3.5.7.0 was used for better results. A useful tool in teaching vocabulary is analysis of corpus data. It provided valuable information for both students and teachers about the use of language in real-life situations. A corpus is a collection of authentic texts (English Text Books of Graduate class) that are stored in an electronic form. Its size can range from a few sentences to millions of words. As it told us about the frequency of vocabulary used in the four English books of graduate level. Linguistic information is typically presented in the form of concordances. A concordance is a list of all the occurrences of a particular word or phrase in a corpus, presented within the context (usually a few words to the left and right of this word). The students were taught the use of corpus with the help of software. After teaching the use of corpus they were given the corpus of Graduate English and asked them to find top 20 vocabulary words with the help of corpus. The examples of tasks performed by the students are presented below by Table No. 2:

Table 2

\begin{tabular}{|c|l|c|c|c|c|c|c|}
\hline Sr. No. & \multicolumn{1}{|c|}{ Noun } & Rank & Frequency & Sr. No. & Verb & Rank & Frequency \\
\hline 1. & He & 22 & 2653 & 11. & Was & 30 & 1374 \\
\hline 2. & It & 27 & 1686 & 12. & Had & 37 & 741 \\
\hline 3. & You & 29 & 1492 & 13. & Said & 45 & 631 \\
\hline 4. & She & 36 & 880 & 14. & Like & 69 & 323 \\
\hline 5. & Man & 48 & 529 & 15. & Do & 70 & 317 \\
\hline
\end{tabular}




\begin{tabular}{|c|l|c|c|c|l|c|c|}
\hline Sr. No. & Adjective & Rank & Frequency & Sr. No. & Adverb & Rank & Frequency \\
\hline 6. & Old & 52 & 453 & 16. & There & 57 & 413 \\
\hline 7. & Good & 124 & 147 & 17. & Then & 59 & 403 \\
\hline 8. & Great & 149 & 120 & 18. & Now & 65 & 366 \\
\hline 9. & Long & 158 & 116 & 19. & More & 96 & 201 \\
\hline 10. & Dear & 192 & 93 & 20. & Well & 97 & 200 \\
\hline
\end{tabular}

Concordances are obtained using the software called a concordancer. DDL is an approach to language learning based on the assumption that the use of authentic language together with a concordancer will enable the learners to observe the language as it is used in real-life situations. The students worked on the data shown on computer screen of concordances produced during class. The teacher supervised the students' work and provided a feedback.

\subsection{Post-Test}

Researcher taught the students with the assistance of corpus and they were taught in a different way. The students were given different kind of assignments on vocabulary, synonyms and antonyms. They were asked to work in pair and also in groups. The students got good percentage after the learning how to enhance vocabulary. Keeping in mind that DDL should be considered just one part of a holistic plan to teach academic vocabulary in the ESP classroom (especially once it has unequivocal empirical support for its implementation), the results of this study have many implications for designing and using this type of activity with college-level students. First, the results have implications for adjusting the design of the DDL activity in order to better scaffold learners and promote more accurate and efficient analyses than those performed in this study. Second, the results have implications for the unique applications of DDL in the teaching of unfamiliar vocabulary; specifically, that the activity may facilitate students" "noticing" of certain aspects of the word that traditional vocabulary learning strategies (i.e., dictionary consultation and guessing meaning from context) either do not cover or that students are not able and/or inclined to take advantage of when using these resources. Finally, the results suggest that DDL may also be a viable technique to teach and test language learners' skill in guessing the meaning of unknown words from context. These results will be discussed further below.

\subsubsection{Post-Test Results}

The following table-III discusses the results of the posttest (Appendix-C) with a focus on the implications for changing and improving the vocabulary used in this study and the unique contributions DDL has to offer to vocabulary teaching in the second language classroom. The students earned good results after the learning as 61 to 92.33 percent. So this shows that the students learned with corpus as a better way as the results show. Most of the students were enhanced their vocabulary. Dull students also show their interest in learning vocabulary through corpus.

The students got highest $100 \%$ marks in the post-test and lowest score earned by the students in the post-test was $85 \%$. The overall percentage was 92.33 earned by the students. The results are shown in the graph and table. The results after the teaching to the students are shown in Table No. 3 and Chart No. 2. 
Table 3

\begin{tabular}{|c|c|c|c|c|}
\hline \multicolumn{5}{|c|}{ Post-Test Results } \\
\hline $\begin{array}{l}\text { Sr. } \\
\text { No. }\end{array}$ & $\begin{array}{l}\text { Vocabulary Test } \\
\text { Q.1. out of } 10\end{array}$ & $\begin{array}{c}\text { Vocabulary Test } \\
\text { Q.2. out of } 10\end{array}$ & Obtained out of 20 & Percentage \\
\hline 1 & 9 & 10 & 19 & 95 \\
\hline 2 & 10 & 9 & 19 & 95 \\
\hline 3 & 9 & 8 & 17 & 85 \\
\hline 4 & 10 & 8 & 18 & 90 \\
\hline 5 & 10 & 10 & 20 & 100 \\
\hline 6 & 9 & 8 & 17 & 85 \\
\hline 7 & 10 & 9 & 19 & 95 \\
\hline 8 & 10 & 10 & 20 & 100 \\
\hline 9 & 9 & 9 & 18 & 90 \\
\hline 10 & 9 & 8 & 17 & 85 \\
\hline 11 & 10 & 9 & 19 & 95 \\
\hline 12 & 9 & 8 & 17 & 85 \\
\hline 13 & 10 & 9 & 19 & 95 \\
\hline 14 & 10 & 9 & 19 & 95 \\
\hline 15 & 10 & 10 & 20 & 100 \\
\hline \multicolumn{4}{|c|}{ Overall Percentage: } & 92.33 \\
\hline
\end{tabular}

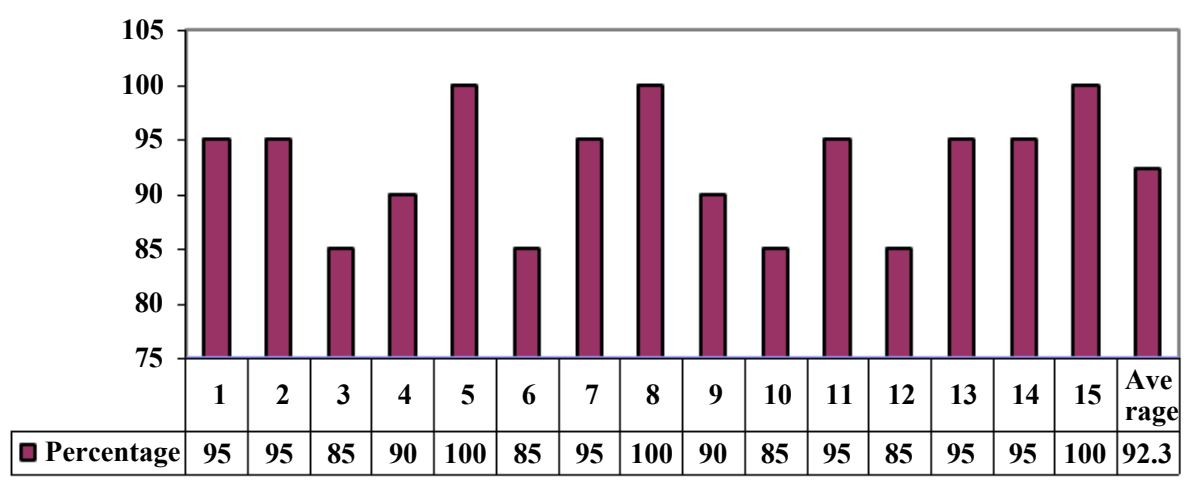

Figure 2

Figure 2 shows the results of post-test of the students. Students 1 got $95 \%$, student 2 got 95 , student 3 got 85 and so on. In the last the average is shown as 92.33 .

\subsection{Pre And Post Test Difference}

Following Table No. 4 shows the difference between the pre and post-test taken by the students. Students showed 31.66 percent better performance in the post-test. This performance is due to corpus based activities. The students were learned through computer in a computer lab and they were asked to search different vocabulary word then they also were asked to search the synonyms and antonyms of the words they already have searched. They were asked to make the sentences by using those all new vocabulary words. They were given different assignments to use new vocabulary words and worked in pair and group. In this way they showed better performance and got good percentage in post-test. 
Table 4

\begin{tabular}{|c|c|c|c|}
\hline \multicolumn{4}{|c|}{ Pre and Post Test Difference } \\
\hline Sr. No. & Pre Test \%age & Post Test \%age & Difference \\
\hline 1. & 50 & 95 & 45 \\
\hline 2. & 65 & 95 & 30 \\
\hline 3. & 50 & 85 & 35 \\
\hline 4. & 55 & 90 & 35 \\
\hline 5. & 65 & 100 & 35 \\
\hline 6. & 50 & 85 & 35 \\
\hline 7. & 75 & 95 & 20 \\
\hline 8. & 90 & 100 & 10 \\
\hline 9. & 60 & 90 & 30 \\
\hline 10. & 55 & 85 & 30 \\
\hline 11. & 50 & 95 & 45 \\
\hline 12. & 50 & 85 & 35 \\
\hline 13. & 70 & 95 & 25 \\
\hline 14. & 55 & 95 & 40 \\
\hline 15. & 75 & 100 & 25 \\
\hline & Overall Percentage: & $\mathbf{3 1 . 6 6 \%}$ \\
\hline
\end{tabular}

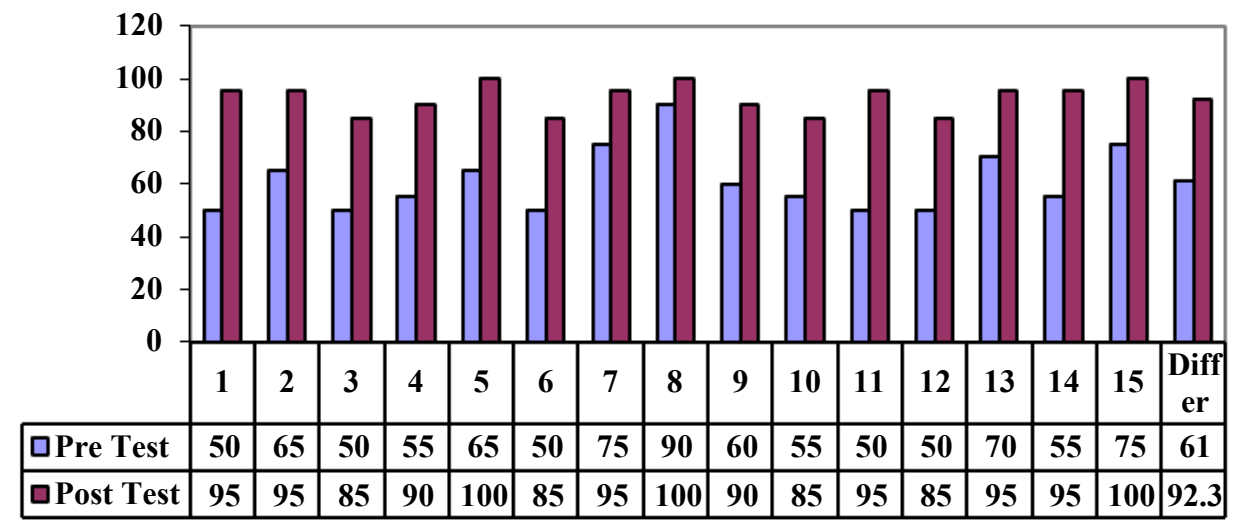

Figure 3

Figure 3 shows the difference between pre and post-test. As student 1 got $50 \%$ marks in pre-test and after the learning he got $95 \%$ marks. Same in the case of student 2 as he got $65 \%$ before and the after he achieved $95 \%$ marks. In the last column of the Chart No. III overall difference is given as overall students' average was before learning was $61 \%$ and after the teaching vocabulary they got $92.33 \%$ marks.

\subsection{Discussion}

The list of the 20 most frequent vocabulary specialized vocabulary and keywords generated by the researcher from the corpora given to the students. In addition, vocabulary and reading comprehension tests were administered.In the tests, both of the questions were related to specialized vocabulary and keywords. The students had to answer the questions regarding reading comprehension questions based on the passages given to the students. The total score 
for the test was 20 points. The test questions had been reviewed by the subject expert, and the tests were scored by the researcher. During the 4th week, the same vocabulary and reading comprehension tests were administered again to investigate the students' progress. Before discussing the results of the study and the implications they have for designing and exploiting DDL activities to teach unknown vocabulary, it is important to place the DDL activity featured in this study in its larger context in the communicative language classroom. In the introduction to his book, Learning Vocabulary in another Language, communicative language course divided into "four strands" of instruction: 1) comprehensible meaning-focused input, 2) language or form-focused instruction, 3) meaning-focused output, and 4) fluency development. These four strands serve as a guide for balancing instruction in the foreign or second language classroom. Furthermore, Nation claims these strands need to be equally employed in the classroom and in homework in order to create a balance in the language course (i.e., $25 \%$ of class/homework time should be spent on each strand). The DDL activity featured in this study clearly falls under strand two of Nation's model, form focused instruction. This said, DDL activities which focus on providing learners with declarative knowledge of the meaning(s), collocate(s), etc. of a word, as did the activity in this study, are merely one part of what should be a more holistic approach to vocabulary teaching and learning; teachers will need to supplement these activities with materials and activities which give learners the opportunity to apply the declarative knowledge of a word they acquire from DDL in meaning-focused and fluency-building activities. One strength of the activity design in this study, however, was that it contained concordance lines which were extracted from the students' assigned texts. Therefore, the students encountered these words in both their meaningful context and in a formfocused, DDL activity.

\section{CONCLUSION}

The results of the vocabulary test indicated that the receptive vocabulary knowledge of the two groups is different. The learners who were taught through corpus-based teaching, performed much better. In addition to delineating clear advantages of using corpus over consulting a dictionary to learn new words, most learners in this study commented that corpus was a more effective activity for learning new words than guessing the meaning of a word from a single context. Furthermore, the results of this study indicate that learners often do not use dictionaries to teach themselves multiple aspects of a word. Therefore, corpus appears to be the most advantageous option for exposing students to a word in multiple, authentic contexts at one time. However, again, future research will need to verify if this is indeed a favorable condition for language acquisition, and if the meaning students report finding in the data actually helps them to use the word when composing longer texts within a given discourse. Students showed good result after the learning of four weeks. The results were $31.66 \%$ better from the pre-test. After using the corpus activities, they were able to make sentences and well known, how to use a new word in their own sentences. They also showed improvement in the use of form of verb in a sentence.

The main goal of this exploratory study was to examine if corpus has something unique to offer in the teaching of vocabulary, warranting its use alongside more traditional vocabulary teaching methods. Furthermore, the study compared the efficacy of two designs on students' noticing of collocations in concordance data. Finally, suggestions were made for improving the overall design of the activity in order to better scaffold students' analyses and make corpus work easier for students to complete. 